BATU MAWE DI TELUK WONDAMA

(Mawe Stone in Wondama Bay)

\title{
Rini Maryone
}

Balai Arkeologi Papua

Jl. Isele, Kampung Waena, Distrik Heram, Kota Jayapura 99358

e-mail: rinimaryone1972@gmail.com

\section{INFO ARTIKEL}

\section{Histori Artikel}

Diterima : 22 Juli 2019

Direvisi : 2 Agustus 2019

Disetujui : 29 November 2019

\section{Keywords:}

megalithich remains, mythology, mawe stone

\section{ABSTRACT}

There are quite a few megalithic interesting topics to studies. Megalithic cultural remains can be studied from all aspects. On this occasion the out her will examine the remain of the megalitithic culture of the mawe stone in the Roon district of Wondama Bay Regency, West Papua Province. This study uses an ethno-archaeological approach and a motodegy approach. The ethno-arhnographic data as analogy to obtain the community cultural model under study. In the end it can projeocted the extinect past culture can help solve archeological problems. While using the mythological approach is expected to be able to give a clear picture of how mythological stories can be received and read by the next generation. This research has been conducted in two stages, namely data collection and data processing. Data collection is done in save ral ways, namely survey, interview and conduct literature studies. The final stages is data processing aftet all the data collected is them described, analyteed, and interpreted. From the megalithic remains and mythology, valves that need to be conveyed to be the community and future generations can taken. the existence of this mythologis has an important rule, one of which is social and culture values. These values provide apicture and experience for the community. Thus the presence of megalithig culture with various valuable information is a starting point for archeological studies as a chan of megalithic culture in the archipelago.

\section{ABSTRAK}

\section{Kata kunci:}

Tinggalan megalitik, mitologi, batu mawe
Tinggalan megalitik di Papua cukup banyak merupakan topik yang menarik untuk dikajih. Tinggalan budaya megalit tersebut dapat dikajih dari segala aspek. Pada kesempatan ini penulis akan mengkaji tinggalan budaya mengalit dari aspek mitologi dan budaya di Papua. Yaitu tinggalan megalitik batu mawe yang berada di Kampung Manerbo, Distrik Roon, Kabupaten Teluk Wondama, Provinsi Papua Barat. Penelitian ini menggunakan metode pendekatan etnoarkeologi dan pendekatan mitologi. Pendekatan etnoarkeologi memanfaatkan data etnografi sebagai analogi untuk memperoleh model kebudayaan masyarakat yang diteliti. Pada akhirnya dapat di proyeksikan kebudayaan masa lampau yang telah punah sehingga dapat membantu memecahkan masalah-masalah arkeologi. Sedangkan dengan menggunakan pendekatan mitologi diharapkan mampu memberikan gambaran secara jelas bagaimana kisah mitologi dapat diterima dan dibaca oleh generasi penerus. Penelitian ini pulah dilakukan dengan dua tahap yaitu pengumpulan data dan pengolahan data. Pengumpulan data dilakukan dengan beberapa cara yaitu : survei, wawancara dan melakukan studi pustaka. Tahap akhir adalah pengolahan data, setelah semua data terkempul kemudian dideskripsikan, dianalisis dan diinterpretasikan. Dari tinggalan megalitik dan mitologinya dapat diambil nilai-nilai yang perlu di sampaikan kepada masyarakat dan generasi penerus Keberadaan mitologi ini memiliki peran yang penting, salah satunya terkandung nilai, sosial, dan budaya. Nilai-nilai inilah yang memberikan gambaran dan pengalaman tersendiri pada masyarakat. Dengan demikian hadirnya budaya megalit dengan berbagai informasi yang sangat berharga ini sebagai titik tolak kajian arkeologi sebagai mata rantai budaya megalitik di Nusantara. 


\section{PENDAHULUAN}

Megalitik berasal dari kata mega yang berarti besar dan lithos yang berarti batu, sehingga dapat diartikan sebagai batu besar (Soejono, 2010). Sebagian besar tinggalan megalitik terbuat dari susunan batuan monolit yang memiliki ukuran relatif besar, seperti menhir, dolmen, ataupun punden berundak. Berdasarkan makna kata dan tinggalantinggalan megalitik tersebut, megalitik selalu dikaitkan dengan budaya batu besar. Tidak hanya terkait dengan budaya batu besar, megalit juga mempunyai keterkaitan dengan pemujan terhadap nenek moyang.hal ini terlihat dari upacara yang dilakukan sebelum mendirikan banguan atau monument megalitik. Upacara itu selalu dikaitkan dengan penghormatan terhadap kematian tetua atau perwujudan rasa hormat mereka terhadap nenek moyang yang telah meninggal. Oleh karena itu, dapat disimpulkan terdapat dua macam fungsi dan budaya megalitik, yaitu berkaitan dengan upacara atau ritual tertentu dan penguburan

Soejono tahun 2010 dalam Sejarah Nasional Indonesia, menyebutkan bahwa budaya-budaya megalitik ini berkembang sesuai dengan corak budaya local/ budaya setempat dalam kondisi masa sekarang (Soejono : 2010 : 448). Budaya lokal/ budaya di Papua menggunakan medium batu-batu alam seperti stalagmit dan stalagtit dalam gua-gua, dolmen, batu pahatan dan batu-batu alam lainnya yang dianggap sebagai jelmaan roh-roh nenek moyang.

Perkembangan budaya megalitik di setiap daerah di Indonesia sangat beragam apabilah dilihat dari lokasi, perkembangan budaya maupun kuantitas tinggalan megalitik, termasuk perkembangan megalitik di Papua. Di Papua banyak tinggalan megalitik yang ditemukan pada puncak gunung. Beberapa penelitian membuktikan hal tersebut antara lain di Pulau Roon ini, yang merupakan tinggalan megalitik batu mawe ini dan mitologi batu tersebut.

Terkait dengan judul tinggalan megalitik dan mitologi batu mawe terlebih dahulu kita pahami apa arti mitos. Istilah mitos dalam bahasa Indonesia berasal dari kata "mythos" (Yunani) yang berarti cerita dewata, dongeng terjadinya bumi dengan segala isinya (Zulfahnur, 1997: 45). Lebih lanjut, Zulfahnur (1997: 46) menjelaskan bahwa mitos juga diartikan cerita perihal dewata, kejadian bumi dan isinya, cerita kepercayaan pada dunia gaib. Menurut Wallek dan Werren (dalam Budianta, 1995 : 243) mitos diartikan sebagai ceritacerita anonym mengenai asal mula alam semesta dan nasib serta tujuan hidup, penjelasan-penjelasan yang diberikan oleh suatu masyarakat kepada anakanak mereka mengenai dunia, tingkah laku manusia citra alam dan tujuan hidup manusia.

Pemakaian istilah zaman dahulu dalam pengertian mitos menandakan bahwa mitos merupakan peristiwa atau cerita yang sudah usang. Berkaitan dengan 
hal gaib isi mitos menyangkut dewa dan pahlawan. Sejalan dengan hal tersebut Chulsun (2006 : 446) mengartikan mitos sebagai cerita tentang pahlawan dan dewa pada zaman dahulu yang dipercaya secara turun temurun. Mitos merupakan milik masyarakat yang bersifat anonim dalam arti tidak bisa dtelusuri siapa pencipta/ pembuat/pencetusnya. Sehingga mitos tersebut dianggap sebagai milik komunal masyarakat setempat. Mitos berkembang di masyarakat dari mulut ke mulut dan umumnya bersifat lisan.

Mitos merupakan sesuatu hal yang dipercayai oleh sebagian orang, biasa dipakai untuk menakut-nakuti, memberi peringatan, ataupun diceritakan secara berkelanjutan. Semua mitos yang ada di dunia, merupakan mitos yang telah ada sejak zaman nenek moyang, dikarenakan cerita yang terus bergulir, atau bisa saja mitos berubah dikarenakan zaman yang terus berkembang. Bagi sebagian orang mitos merupakan sesuatu yang sudah jarang dipercaya, tapi masih juga ada yang percaya tentang mitos-mitos tertentu dan terus bergulir sampai sekarang, seperti mitos mengenai Sinterklas, yang sampai sekarang masih dipertanyakan keberadaannya.

Pengertian mitos yang ada di dalam buku Teori Sastra: Kajian Teori dan Praktik, yaitu: persamaan mitos di berbagai tempat bukan disebabkan difusi (penyebaran) melainkan disebabkan penemuan-penemuan yang berdiri sendiri. Mitos-mitos itu dapat mirip satu sama lain, karena adanya yang disebut Carl
Jung sebagai kesadaran bersama yang terpendam pada setiap umat manusia yang diwarisinya secara biologis (Rafiek, 2010:55).

Jadi secara sadar atau tidak mitos yang sampai sekarang masih juga dipercayai merupakan mitos yang telah ada sedari dulu dan berkembang. Maka hal tersebut menjadi sesuatu yang dipercayai bersama. Pengertian mitos juga diterangkan oleh Audifax di dalam bukunya yang berjudul Mite Harry Poter: Psiksemiotika dan Misteri Simbol di Balik Kisah Harry Potter, dengan menerangkan perbedaan antara mitos, cerita rakyat dan juga legenda dapat dilihat dari sumber di bawah:

Mitos di dalam bukunya berarti cerita dari masa lalu. Mitos menjelaskan esensi kehidupan dan dunia atau mengekprisikan adanya nilai moral budaya dalam kehidupan manusia. mitos memberi perhatian pada kekuatan yang mengontrol kehidupan manusia dan relasi antara kekuatan tersebut dengan keberadaan manusia. Meski mitos kerap memiliki nilai religi dalam bentuk dan fungsinya, namun mitos ditenggarai merupakan bentuk awal dari sejarah sains, atau filsafat (Audifax, 2005 :5).

Mitos memang berbeda dengan cerita rakyat atau folklore juga dengan legenda, karena mitos tidak hanya merupakan sebuah cerita, tapi juga dipercaya adanya, dan hal itu jadi berubah sesuai zamannya. Kepercayaan terhadap mitos akan terus ada, berbedabeda dan berkembang seperti yang dilihat 
di paragraph sebelumnya, tidak hanya terjadi karena cerita yang turun temurun, tetapi juga karena adanya perasaan yang terepresikan terhadap diri seseorang, yang terus menerus ditekan maka perasaan yang depresi tersebut dapat dijadikan sebuah kepercayaan.

Bruevand menuliskan dalam Danandjaja (1986 : 169) bahwa latar belakang mengapa mitos masih bertahan sampai hari ini di tengah-tengah masyarakat yang modern dapat dijelaskan dengan berbagai kategori. Misalnya, disebabkan oleh cara berpikir yang salah, koinsiten, predileksi (kegemaran) secara psikologis umat manusia untuk percaya pada yang gaib, ritus peralihan hidup, teori keadaan dapat hidup terus (survival). Perasaan ketidak mampuan akan tujuantujuan yang sangat didambakan, ketakutan akan hal-hal yang tidak normal atau penuh resiko bahwa tenaga gaib dapat tetap hidup berdampingan dengan ilmu pengetahuan dan agama, salah satunya budaya mitos batu mawe ini.

Penelitian ini menggunakan metode pendekatan etnoarkeologi dan metode pendekatan mitologi. Menurut Sukendar (Wibiwo, 2015 : 17) etnoarkeologi adalah studi arkeologi sebagai analogi untuk membantu memecahkan masalah-masalah arkeologi. Kajian etnoarkeologi bukan untuk menjelaskan gejala yang dapat diamati saat ini (data etnografi), tetapi sekedar memberikan gambaran kemungkinan adanya persamaan antara gejala budaya masa lampau dan masa kini. Metode pendekatan mitologi diharapkan penelitian ini mampu memberikan gambaran secara jelas bagaimana kisah mitologi batu mawe dapat diterima dan dibaca oleh generasi penerus Selain itu penelitian ini dapat memberikan informasi kepada masyarakat luas mengenai mitos batu mawe dan khususnya masyarakat Pulau Roon.

Penelitian ini, dilakukan dengan dua tahap yaitu pengumpulan data dan pengolahan data. Pengumpulan data dilakukan dengan beberapa cara yaitu: survei dengan pengamatan langsung terhadap objek yang diteliti. Wawancara dengan beberapa tokoh-tokoh guna mendapatkan informasi tentang objek yang diteliti. Melakukan studi pustaka dengan menelaah beberapa pustaka yang berkaitan dengan objek penelitian setelah semua data yang dibutuhkan terkumpul. Tahap akhir adalah pengolahan data, setelah semua data terkumpul kemudian dideskripsikan, dianalisis dan diinterpretasikan.

\section{PEMBAHASAN}

Daerah penelitian terletak di Kabupaten Teluk Wondama adalah salah satu kabupaten di Provinsi Papua Barat, Indonesia, ibukota kabupaten ini terletak di Wasior. Kabupaten ini mulai terbentuk sebagai hasil pemekaran kabupaten Manokwari berdasarkan UU Nomor 26 Thun 2002. Kabupaten Teluk Wondama terletak pada titik koordinat $0^{0} 15^{\prime} \mathrm{LS}$ dan $132^{\circ} 35^{\prime}-134^{0} 45^{\prime}$ BT.dengan luas $3.959 .53 \mathrm{~km}^{2}$. . Dengan batas wilayah Kabupaten Teluk Wandama sebelah utara Distrik Tahota Kabupaten Manokwari dan Teluk Cenderawasih, sebelah selatan Distrik Yaur Kabupaten Nabire, sebelah 
Barat Distrik Kuri dan Distrik Idoor, Windesi adalah Gunung Tasabuar yang Kabupaten Teluk Bintuni dan sebelah ketinggiannya mencapai 868 meter timur Distrik Teluk Umar Kabupaten (Badan Pusat Statistik Kabupaten Teluk Nabire.

Pembagian daerah aministrasi Wandama, 2011).

Penelitian difokuskan di Pulau terdapat 13 distrik, 1 kelurahan dan Roon yang masuk dalam kawasan wilayah 75 kampung, tahun 2017 (http:/www. wondamakab.go.id). Distrik di Kabupaten Teluk Wandama adalah Distrik Kuri Wamesa, Rumberpoon, Wamesa, Wasior, Wasior Barat, Wasior Selatan, Wasior Utara, Windesi, Duariri, Wondiboy, Rasiey, Naikere, Roon. Topografi wilayah Kabupaten Teluk Wandama sebagian besar adalah pegunungan dengan ketinggian gunung yang relatif berbeda-beda. Di Kabupaten Teluk Wandama terdapat beberapa gunung yang ketingiannya lebih dari 500 meter. Gunung yang tertinggi adalah Gunung Wandiboy dengan ketinggian 2.340 meter yang terletak di Distrik Wasior. Sedangkan gunung-gunung lainnya tersebar di Distrik Wasior dan Distrik Windesi. Sedangkan gunung tertinggi yang terdapat di Distrik

Distrik Roon. Secara geologis Distrik Roon terdiri atas gugusan beberapa pulau kecil yang tersebar dengan jarak antara pulau dengan pulau lainnya agak berjauhan, pulau-pulau yang masuk dalam wilayah tersebut diantaranya adalah Pulau Mioswar, Pulau Roswar, Pulau Matar dan Pulau Yanggoandi.

Lingkungan vegetasi Pulau Roon pada umumnya adalah vegetasi pantai dan gunung. Vegetasi pantai berupa tanaman pohon kelapa, tanaman jenis pandan, palem, tanaman bakau serta pohon bambu. Sedangkan tanaman kebun pisang, jeruk nipis, umbi-umbian dan kacang-kacangan. Selain itu terdapat pohon matoa, pohon genemo, pohon mangga dan jenis pohon lainnya.

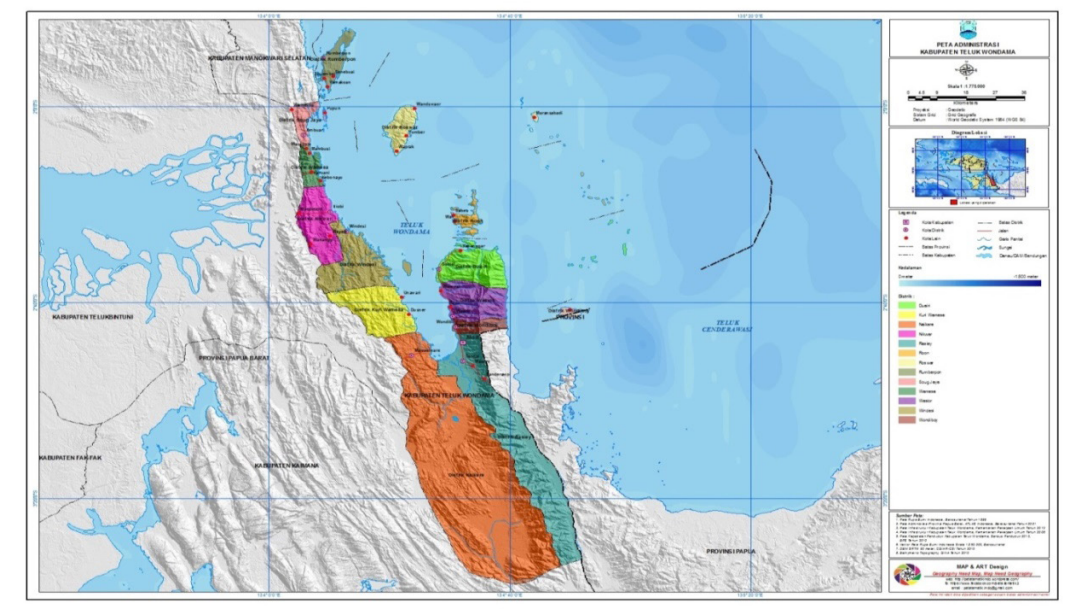

Peta 1. Kabupate Teluk Wondama 
Masyarakat Pulau Roon sebagian besar mata pencahariannya sebagai nelayan mereka menggantungkan hidupnya pada hasil laut. Nelayan di Kabupaten Teluk Wandama dalam melakukan aktifitasnya menangkap ikan menggunakan perahu dayung, dan perahu motor. Alat yang digunakan untuk menangkap ikan berupa pancing, jala, jaring, senapan air, kalawai, bagan dan lain-lainnya. Selain sebagai nelayan mereka membuka kebun untuk menanam sayuran dan umbi-umbian. Jenis sayuran seperti kangkung, kacang panjang, bayam dan lainnya. Sedangkan jenis umbiumbian seperti singkong, petatas dan jenis umbi-umbian lainnya.

Temuan batu mawe, terdapat di Kampung Manerbo, Distrik Roon dimana pusat pemerintahannya berada di Kampung Yende. Wilayah ini merupakan kepulauan, dahulu Yende bernama Roon, sebelumnya kampung ini termasuk dalam wilayah Distrik Wasior Utara (Mene, 2016 : 10).

\section{Mitos Batu Mawe}

Survei pada Kampung Manerbo ditemukan batu mawe. Situs ini oleh masyarakat setempat diberi nama kanggoandi yang artinya tempat istirahat. Situs Kanggoandi berada pada titik koordinat S $02^{0} 393^{\prime} 90^{\prime}$ dan E 1340576'70". Posisi batu mawe berada didepan pohon beringin menghadap ke timur laut. Vegetasi situs ditumbuhi pohon matoa, cempedak, pohon kayu jati, beringin sejenis pandan, palem genemo dan jenis pohon lainnya. Posisi batu mawe berada didepan pohon beringin, ukuran batu mawe, panjang $37 \mathrm{~cm}$, lebar $24 \mathrm{~cm}$ dan tebal $9 \mathrm{~cm}$ (Mene : 2016 : 13).

Menurut mitos masyarakat di Pulau Roon, konon batu ini dipercaya dapat mengabulkan keinginan seseorang. Mitos batu mawe ini, apabila seseorang berhasil mengangkat batu mawe tersebut, dengan enteng dan tidak mengalami kendala/ ringan maka keinginan seseorang itu akan terkabul. Sebaliknya apabilah batu mawe ini diangkat mengalami kendala, terasa batu itu berat dan menjatuhkan batu mawe ini maka keinginannya tidak akan terkabulkan. Kepercayaan akan mitos batu ini masih di percaya sampai saat ini. Biasanya apabila seseorang mau merencana sesuatu misalnya berencana mau menikah atau menemukan jodoh, bepergian jauh, dan keinginan-keingnan lainnya mereka akan naik ke puncak gunung ini dan melakukan tradisi/ ritual mengangkat batu mawe tersebur. Mitos ini masih dipercaya oleh orang modern sampai saat ini sebagai petunjuk hidup mereka. Ada kecenderungan mitos ini memiliki kedudukan terpenting kedua setelah agama. Dalam tradisi mitos yang berada di tengah-tengah kehidupan masyarakat dapat dilestarikan melalui dongeng, tembang, kepercayaan rakyat, simbol, sengkahan dan bangunan tertentu. 

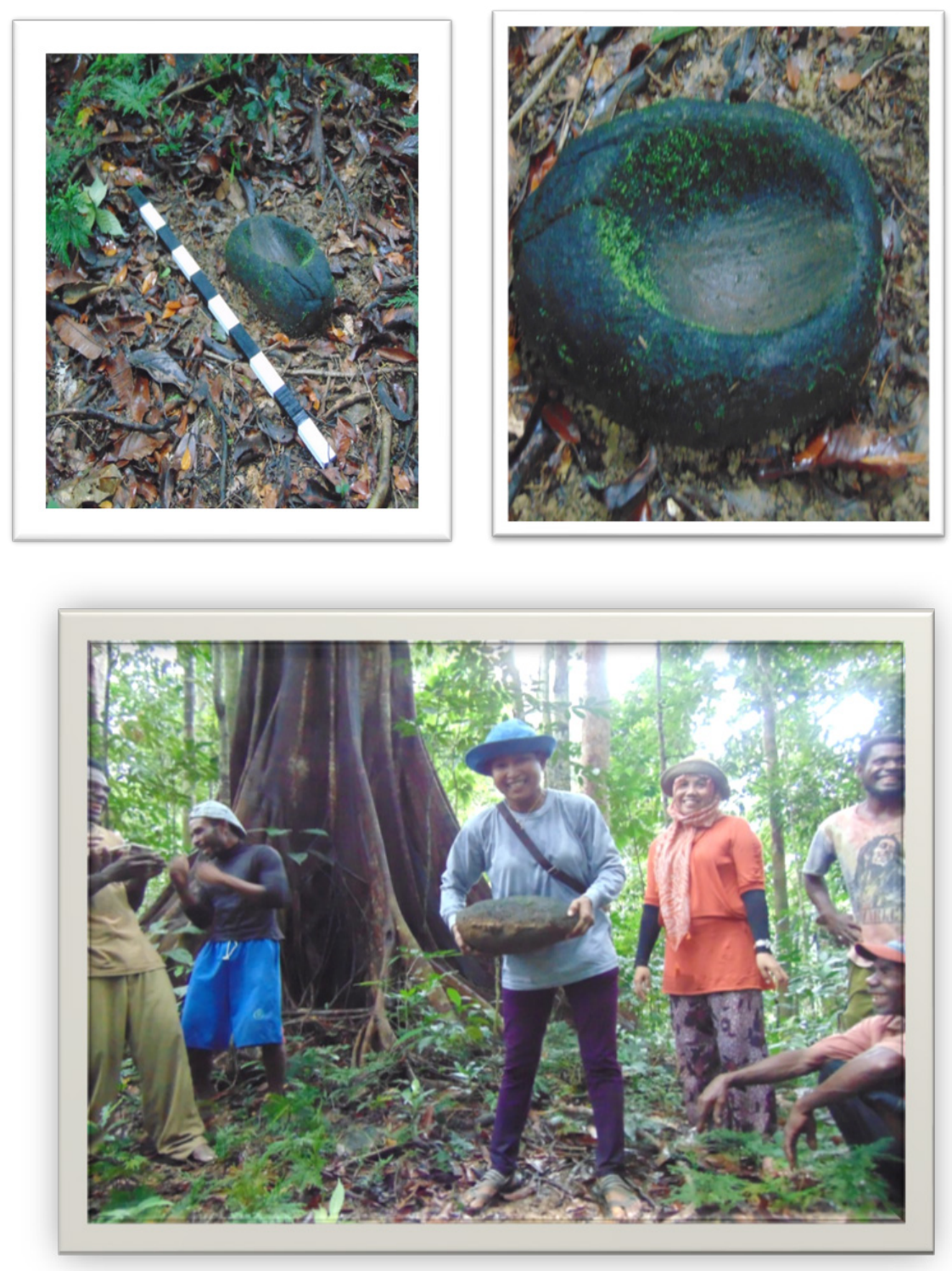

Foto 1. Batu Mawe (dokumentasi Rini Maryone)

Sebuah mitos digali bukan soal dengan mempercayai banyak nilai-nilai kebenarannya tetapi soal sebuah nilai. kehidupan.

Dituturkan supaya berguna untuk seluruh Erat kaitanya antara sebuah manusia. Sebuah tujuan mitologi ialah kisah mitologi dengan sebuah nilai menyampaikan nilai yang tersirat dengan yang terkandung didalamnya. Nilai gambaran sebuah fenomena yang begitu yang dimaksud adalah apa yang diambil imajinasif. Maka tak heran jika pola oleh masyarakat kisah mitologi dan hidup masyarakat Papua khususnya di mengetahui secara jelas maksud dari Kampung Manerbo terkesan religius, kisah mitologi tersebut. Maka defenisi karena mereka menyakini bahwa epos nilai itu sendiri sama halnya jika dikaitkan ini dituturkan untuk kebaikan mereka pada segala aspek kehidupan manusia, 
misal kita bisa mengambil nilai dari kebudayaan, entah berupa pesan moral ataupun material nyata (peninggalan suatu kebudayaan). Maka alasan atau sebuah nilai dari ilmu pengetahuan yang digunakan sebagai pengetahuan wawasan manusia. Nilai pada mitologi tersebut mempunyai harapan bagaimana manusia yang baik seharusnya, dapat menarik sebuah nilai. Karena nilai paling penting pada sebuah mitologi adalah gambaran kehidupan manusia pada kenyataannya.

Hadirnya sebuah kisah mitologi merupakan sebuah kerangka awal jalan pikir manusia menciptakan sebuah mitos sebagai bentuk rasionalitas atau dalam bahasa lain, manusia mulai memikirkan segala sesuatunya secara radikal dan mulai dipenuhi sebuah penasaran. Terlepas dari sebuah keyakinan, mitologi yang penah ada memiliki nilai-nilai secara inplisit yang menghendaki manusia mampu memaknai nilai tersebut dalam kehidupanya. Bahkan peran mitologi juga besar pada kelahiran filsafat. Mitologi membuka dimensi nilai kehidupan, dimana akal dan pengalaman tidak ada. Kekosongan yang hanya dapat diisi dengan sebuah hikmat.

Selanjutnya pentingnya mengkaji nilai-nilai yang terkandung dalam cerita mitos karena cerita mitos ini memiliki fungsi kultural. Lahirnya suatu cerita mitos bukan semata-mata di doronng oleh keinginan penutur untuk menghibur masyarakatnya melainkan dengan penuh kesabaran ia ingin menyampaikan nilainilai luhur kepada generasi penerusnya.
Dari uraian cerita mitos batu mawe ini ada khasanah budaya yang tersirat, dan pesan moral yang dapat dipetik diantaranya: memberi pesan bahwa manusia tidak mampu untuk melakukan ini dan itu tanpa kekuatan dan bantuan orang lain atau kekuatan yang dianggap lebih dari dirinya. Cerita mitos batu mawe ini merupakan inspirasi yang menarik untuk dieksplor dan diekspos pada khalayak umum sebagai khasanah pengembangan ilmu budaya, yang merupakan perbendaharaan pemikiran warisan nenek moyang yang berguna juga untuk masa sekarang sebagai alat pendidik kepada masyarakat.

Keberadaan mitos ini memiliki peran yang penting, salah satunya terkandung nilai sosial nilai budaya. Nilai-nilai inilah yang memberikan gambaran dan pengalaman tersendiri pada masyarakat. Nilai-nilai tersebut dapat di uraikan sebagai berikut: nilai sosial, adalah suatu pandangan yang dianggap baik dan benar dapat dijadikan pedoman dalam berprilaku, Nilai-nilai tersebut berkaitan dengan nilai keagamaan, kebaikan serta etika. Nilai budaya, Nilai-nilai yang disepakati oleh semua anggota masyarakat, berdasarkan nilainilai penting, yang termasuk nilai budaya yaitu: hubungan, keamanan keluarga, status sosial, keharmonisan kelompok, dan spiritualisme. Nilai-nilai inilah yang memberikan gambaran dan pengalaman tersendiri pada masyarakat. 


\section{PENUTUP}

Tinggalaan megalitik batu mawe yang berada di puncak gunung di Kampung Manerbo, Pulau Roon dan kepercayaan mitosnya sudah ada sejak turun temurun dari generasi-kegenerasi. Tinggalan megalitik batu mawe konon dipercaya dapat mengabulkan keinginan seseorang. Mitos batu mawe ini, apabilah seseorang berhasil mengangkat batu mawe ini dengan enteng dan tidak mengalami kendala/ ringan maka keinginan seseorang itu akan terkabul. Sebaliknya apabilah batu mawe ini diangkat mengalami kendala, terasa batu itu berat dan menjatuhkan batu mawe ini maka keinginannya tidak akan terkabulkan.

Erat kaitanya antara sebuah kisah mitologi dengan sebuah nilai yang terkandung didalamnya. Keberadaan mitos ini memiliki peran yang penting, salah satunya terkandung nilai sosial nilai budaya. Nilai-nilai inilah yang memberikan gambaran dan pengalaman tersendiri pada masyarakat. Keberadaan mitos ini memiliki peran yang penting, salah satunya terkandung nilai, sosial, dan budaya. Nilai-nilai inilah yang memberikan gambaran dan pengalaman tersendiri pada masyarakat.

\section{DAFTAR PUSTAKA}

Audifas. 2005. Mite Harry Potter: Psikologi, Semiotika dan Misteri Simbol Dibalik Kisah Harry Potter. Terbitan Jalasutra.

Teluk Wondama dalam Angka. 2011. Badan Pusat Statistik Kabupaten Teluk Wandama.

Chulsum. W. N. 2006. Kamus Besar Bahasa Indonesia. Surabaya: Kashiko.

Danadjaja. J. 1986. Folklor Indonesia: Ilmu Gosip, Dongeng dan Lain-Lain. Jakarta: Grafiti.

D. T. K. 2008. Pengolahan dan Analisis Data Penelitian. Jakarta: Direktorat Jenderal Peningkatan Mutu, Pendidik dan Tenaga Kependidikan, Departemen Pendidikan Nasional.

Eliade. M. 2002. Mitos: Gerak Kembali yang Abadi, Kosmos dan Sejarah. Yogyakarta: Ikon Teralitera.

Mene, Bau. 2016. Laporan Penelitian Pengaruh Budaya Ausrtonesia di Kabupaten Teluk Wondama. Balai Arkeologi Papua.

Soejono. 2010. Sejarah Nasional Indonesia. Jakarta. Balai Pustaka.

Spranley. James. P. 1997. Metode Etnografi. Terjemahan. Yogyakarta. Tiara Wacana.

Zulfahnur 1997. Teori Sastra. Jakarta: Depdikbud.

\section{INTERNET}

http:/www.wondamakab.go.id diakses 14 Juli 2014 pukul 08.00 WIT 